\title{
Workforce Diversity and Performance of Kisumu Law Courts, Kenya
}

\author{
Onyango Maureen Anyango \\ Oluoch Mercy Florah \\ University of Nairobi \\ School of Business \\ Kenya
}

\begin{abstract}
Diversity issues have drawn a lot of concern to most organizations and created lot of debate on its benefits as well as the challenges that come with the acceptance of the same. While diversity has been argued to be a driving force to performance improvement in organizations, at Kisumu Law Courts Kenya issues in delay in resolving cases that creates backlog has been a great concern. This is because the organization is entirely dependent on its workforce to facilitate and fast track case resolutions. Efforts to increase the workforce and manage through mediation processes have produced little results as the same complains have been rose overtime thus warranting this study. The main objective of the study was to identify to what extent gender, ethnicity, religion and educational background influenced performance at Kisumu Law Courts. The study adopted longitudinal research design in its methodology where secondary data derived from the published annual reports to collect data for a period of 10 years showing quarterly reports on the performance of the organization was used and the annual mean organizational performance calculated. Personnel records of the institution were used to reveal the demographic details about employees.Tables were used to present data. Multiple regression was used to find out the predictors of organizational performance and to show a relationship between the variables. Findings indicated the gender diversity was positively related to organizational performance with a value of 0.04.This is because $p<0.05$.An increase of gender diversity increases organizational performance by 1.269 units. On education 0.071, religion 0.061 and ethnicity diversity 0.487 there was no association to organizational performance because the findings were statistically insignificant as $p>0.05$. The study recommends that policies and regulations should be given more to address the challenges of work force diversity. More emphasis should be given to promote career progression and advancement to improve employee knowledge and skills
\end{abstract}

\subsection{Background}

Diversity issues have drawn much concern to most organizations and have spurred a lot of debate on its benefits as well as the challenges that come with the acceptance of the same. Due to globalization, improved educational systems and technological advancements that have brought diverse people together, many organizations that strive to attract and retain highly productive workforce must encourage workforce diversity (Gupta, 2013). The desire to gain competitive advantage, build organizations reputation and to have a wide range of knowledge and skills to enhance performance has made diversity to be widely utilized as an important organizations resource (Adler, 2005).

People are diverse in ways that can be seen or unseen through genetically orientation, religious beliefs and by their position in the society (Kossek, Lobel, and Brown, 2005). The differences therefore create a pool of rich knowledge and skills required to ensure good performance which can be created by recruiting people from diverse backgrounds. According to Greenberg, (2004), organizations that embrace workforce diversity are highly profitable and productive in nature. The concept of workforce diversity therefore addresses the need of not for profit and profit making organizations to recognize the need to embrace diversity not as a legal obligation but as a tool to attaining organizations strategic goals.

The study was premised by the social identity theory that argues that an individual character is driven by both interpersonal and intergroup behavior. It further states that individuals identify themselves in the society and appreciate their value by comparing their relations to their fellow group members. Cognitive diversity relates to how individuals differ from each other in terms of knowledge, perception and experiences. The team work within the working environment fosters organizations success through creativity and innovation as a result of a pool of perspectives of the members that exist within. For the purpose of this study Kisumu Law Courts was identified because it exists in a different societal setting and location in Kenya (Budhwa, 2009) thereby providing a strong background in understanding diversity in the organization. 
Just like any other organization in Kenya is affected by rapid changes and developments such as the promulgation of the Kenyan constitution that demands all organizations to embrace workforce diversity as a legal requirement, Kisumu Law Courts is not exceptional as it derives staff from diverse backgrounds thus posing benefits and obstacles that need to be addressed.

Lastly, being an institution charged with the responsibility of administering justice even though many researches has been done, none of them can be compared to Kisumu Law Courts in terms of service delivery and performance (Magoshi and Chang, 2009).The study will focus on diversity dimensions such as gender, education, religion and ethnicity because there exists previous literature on their relevance to performance of organizations.

\subsubsection{Workforce Diversity}

Workforce diversity encompasses people from different backgrounds coming together to achieve the goals of an organization. Workforce diversity strives to utilize the employee diverse strengths and weaknesses irrespective of their demographic characteristics to ensure success within the organization (Daft, 2008). Workforce diversity seeks to address the different knowledge, skills and abilities that every employee contributes so as to achieve performance. To achieve organizational success, it must a well-managed diversity at their workforces (Aydin, 2013).People are diverse in ways that can be seen or unseen through genetically orientation, religious beliefs and by their position in the society (Kossek, Lobel, and Brown, 2005).Diversity therefore includes all the individuals at the work place who are different irrespective of their gender, religion, education and ethnicity that this study seeks to establish how it affects performance of organizations.

The need to embrace diversity has pushed organizations to recruit from a diverse employee base with a lot of belief of its benefits on how organizations perform. These differences pose both opportunities and obstacles that impact on how organizations deliver their services. Many researches have tried to find out how workforce diversity relates to organizational performance; however, some researches have revealed no relationship at all between the two variables in relation to organizational performance (Marimuthu et al...) Education diversity is the level of literacy of individuals in different perspectives depending on the knowledge and skills that they possess. In most cases, organizations have mostly utilized education diversity as a tool to motivate and influence employees to perform better (Tracy and David, 2011).Education diversity therefore impacts positively on performance of the employees that impact also on the organization (Horwitz,2005).

Gupta, (2013) relates ethnic diversity to organizational performance. This means therefore that the more an organization has an ethnically diverse workforce, productivity will increase and hence performance of the organization. Gender diversity refers to the sexual orientation and identification of a human being.The difference is the culturally accepted identity of a person's genetical orientation (Ali, Kulikand Metz, 2011) .It may have a negative - positive relationship in performance. For many decades, issues of gender and their inclusion at work have been treated with a lot of stereotyping and biasness. An organization that appreciates gender balance builds a strong corporate image as well as attracting highly skilled employees that influence organizational performance.It is also argued that the gender differences possess different strength either as individuals or collectively as a group that leads to a generation of more innovative ideas, wide range of skills and knowledge that drives performance that enable organizations to achieve strategic goals. It also provides great solutions and promotes work achievements as a result of gender inclusion in the organization. Different gender orientation possesses different strengths and weaknesses that when joined together and improved can be a great milestone.

Diversity in religion is the fact that there are significant differences in religious beliefs and practices among individuals. Most employees value much their religion because of what they believe in. Religious practices and beliefs differ in many ways such as the values, behavior, celebrations and to some extent mode of dressing. This is evident in the type of difference in dressing between the Muslims and Christians. Due to diversity differences religious struggles and issues have come up which relatively affects the overall performance that if not properly handled may easily lead to rise in conflicts within the organization. Religion places importance on intellectual beliefs (Byrrand Scott, 2014).Religious discriminations affects employee commitment and engagement as it impacts negatively on work teams and social interaction that may enable people to work collectively in harmony (Byrd and Scott,2014).

\subsubsection{Organizational performance}

Ongeti, (2014) defines organizational performance as the relationship that occurs between efficiency, effectiveness, financial stability and the desire to remain relevant in operations. Generally performance is related to how best an organization can perform by utilizing the limited available resources in accomplishment of the organizational goals (Cole, 2004). 
Organizations are struggling to achieve good performance that can be more realized and effective if the issue of workforce diversity is adopted as the best practice. It therefore leads to highly skilled employees who are motivated to achieve better performance (Harold and Vincent, 2012). Therefore the performance of any organization is dependent on its human resource who are not just people but individuals with a variety of skills, knowledge and abilities that can be well utilized in driving the organization to greater heights in terms of performance.

\subsubsection{The Kisumu Law Court, Kenya}

The organization is composed of the Court of appeal, the High Court, Chief Magistrate's court and the Kadhis court that deals with matters related to the Muslim religion (Judiciary organization structure, 2015).Its core mandate is to provide quick access to justice to all the residents within Kisumu and its environs. For the purpose of this study Kisumu Law Courts was identified because it exists in a different societal setting and location in Kenya (Budhwa, 2009) thereby providing a strong background in understanding diversity in the organization. Just like any other organization in Kenya is affected by rapid changes and developments such as the promulgation of the Kenyan constitution that demands all organizations to embrace workforce diversity as a legal requirement, Kisumu Law Courts is not exceptional as it derives staff from diverse backgrounds thus posing benefits and obstacles that need to be addressed. Lastly, being an institution charged with the responsibility of administering justice even though many researches has been done, none of them can be compared to Kisumu Law Courts in terms of service delivery and performance (Magoshi and Chang, 2009).The study will focus on diversity dimensions such as gender, education, religion and ethnicity because there exists previous literature on their relevance to performance of organizations.

\subsection{Research Problem}

Workforce diversity has been argued as previously to have a contribution to the performance of organizations. This is because a diverse workforce provides a great pool of knowledge skills and experience that when properly utilized can improve organizational performance. Recognizing workforce diversity is crucial so asto ensure of a competition within the environment (Mercy and Rachael, 2013). Previous studies done locally on workforce diversity and organizational performance for instance Busolo, (2017) found out that age, gender and ethnicity were significant factors in determining organizational performance in order to obtain competitive edge and workforce sustainability at AAR Group.

Another study done by Recadina and Ouma, (2017) utilized descriptive survey research design and structured questionnaires. It established that age, occupation and professional network diversities influenced the performance of the board of NGO's in Nairobi County that impacted on the overall performance of the organization. Regionally Olesegun et al, (2017) study on the influence of workforce diversity on Organizational performance in Nigeria found out that employee communication and talent availability influenced organizational performance. Globally a study done Kerby and Burns, (2012) on the contribution of workforce diversity in the USA economy found that out that the nations entire workforce have become more diverse mostly influenced by various gender dimensions lead to a highly productive workforce. Another study by Gupta (2013) found out that age, ethnicity was great contributors to performance of organizations.

Just like any other organization in the contemporary world, Kisumu Law Court is not exceptional in challenges of its human resource derived from diverse backgrounds in order to ensure good performance. Performance issues related to the delay in handling cases to conclusion within the specific timelines has strained service delivery that has led to frequent customer complains. The contributory factor to the performance of the organization is the workforce that provides a strong basis to the achievement. From the studies there is a lot of inconsistencies on the extent to which the demographic variables affect organizational performance. Further that the researches only focused on age, gender and culture as the only variables that affect performance. These studies only looked at non - governmental institutions within a different geographical region and setting and therefore their performance cannot be measured to public institution specifically the government institution leaving a gap that this study seeks to fill by finding out how workforce diversity affects the performance Kisumu Law Courts, Kenya.

These studies only looked at non - governmental institutions within a different geographical region and setting and therefore their performance cannot be measured to public institution specifically the government institution leaving a gap that this study seeks to fill by finding out how workforce diversity affects the performance Kisumu Law Courts, Kenya.

\subsection{Research Objectives}

The objective of the study was to determine the influence of workforce diversityon the performance of Kisumu Law Courts, Kenya. 


\subsection{Theoretical Framework}

The proposed study is pegged on two theories which the researcher will use to explain the workforce diversity which is the variable understudy. The theories are social identity theory and cognitive diversity.

\subsubsection{Social Identity Theory}

It was fronted by John Turner and Henry Tajfet in the late 1970s.According to this theory the behavior of a person and self-conception is influenced by his or her association to other groups. It tends to explain how individuals identify themselves within a societal setting. It further explains that individuals are able to define their place in the society within three psychological processes; social categorization which refers to how people perceive themselves and others within social categories, social comparison where individuals can determine the value of social groups and its members and also through social identification where people are able to know themselves well and their relation and perception to the individuals or groups around them. Generally, this theory posits that a person character is influenced by both interpersonal and intergroup behavior.

\subsubsection{Cognitive Diversity}

This theory postulates that individuals within a particular team differ from each other due to their knowledge, perception and experiences. It involves how people use their intellectual abilities in solving problems and enhancing innovation which becomes the driving factor that enable organizations to achieve their performance target. It further explains the extent to which people are able to work with and handle complexity within the organization. The fact that people within the organization are diverse in nature, they bring rich different perspectives that enable organizations to easily adjust to work challenges, identify new opportunities for growth and threats that may be addressed which offers competitive advantage. Generally, this theory focuses on how unobservable diversity characteristics affect an organization and how teams within the working environment use different approaches in promoting creativity and innovation.

\section{3 Workforce diversity and organizational performance}

With the world turning into a global village, organizations are in the pressure to accommodate people from different backgrounds in order to promote cohesion and social justice (Aydin, 2013). This has prompted various researches done worldwide on diversity issues and its effect on performance. Kerby and Burns, (2012) studied diversity in relation to the economy of the State study found that out a diverse nation is important in boosting the economy of the country due to fair treatment equal gender representation, transgender acceptance made significant influence to the performance of the country. A study by Gupta, (2013), also found out that out age, ethnicity and gender and how they impacted on organizational performance, Kundu et al., (2016) on employee perception on diversity employed against organizational practices in India employed factor analysis, variance and regression models as methodologies used in this research. The study found out that the employees appreciated diversity, however, there were mixed reactions whether gender and value of diversity positively impacted on performance.

Olesegun et al., (2017) on study in Nigeria measuring adopted descriptive survey and use of structured questionnaires as the research methodology administered to 400 employees. The study found out proper communication means helped in reducing conflicts within the organization that ensured well managed diversity issues of the organization which was driven by the open door communication policy between the employees and the top management. On talent availability, the researchers found out that it is the driving factor in retaining employees in the organization because when the available talents are diverse then it means that organizations can securely retain highly skilled employees that would in turn promote organizational performance.

Kyomugisha, (2016), carried a study on international NGOs in Kenya where 50 employees of the organization responded through use of structured questionnaires and descriptive survey design. The study found out that balanced recruitment and diversity training influenced organizational performance of NGOs in Kenya.

Recadina and Ouma, (2017) study focused on how age, occupation and professional networks affected the performance of the board members of the NGOs. It utilized descriptive survey and structured questionnaires as a method of collecting data and hence analyzed using the thematic analysis and spearman correlation co- efficient for both qualitative and quantitative data respectively. The researchers concluded that the variations in age and having diversified age groups composing members of the board contributed greatly to its performance, occupational diversity also affected performance of the board to a greater extent this because people with different skills are very productive especially in helping the board make informed decisions for the organizations that also influence its performance and professional networks also affected the performance of the board as advice on particular areas were made easily and quickly as everything required was available under the same roof that also ensured efficiency in meeting organizational objectives. 
Egondi and Mathuva study on the performance of Cargo Freight stations utilized descriptive method and collected data using close-ended questionnaires. It established that diversity in gender contributed to positive performance of the organization positively; ethnic diversity revealed a negative correlation against performance as a result of discrimination due to ethnic background.

Busolo, (2017) sought to determine the impact of workplace diversity and organizational performance where 90 employees were studied at AAR group by using descriptive research design and questionnaires as methodologies. The study sought to establish to what extent ethnicity, genetical orientation and gender diversity affected performance. The study found out that gender and ethnicity were significant factors in determining organizational performance in order to obtain competitive edge and workforce sustainability at AAR Group.

Even though many studies agree that workforce diversity influence the performance of organizations, some studies have found no relationship at all. For instance Marimuthu et al., (2009) study on ethnicity and genetical orientation on the financial performance of companies in Malaysia found no relation between the diversity variables on top management performance of the companies. Leonard et al.,(2003) study of sale companies found out that gender impacted negatively on the company sales.

\subsection{Summary of gaps.}

From the studies there is a conceptual gap as the studies only sought to address demographic diversity constructs such as age, gender and ethnic background while this study will look at gender, ethnicity, religion and education.. The methodology utilized is descriptive research design and use of structured questionnaires therefore revealing the uniqueness in this study as it will employ use secondary data and longitudinal research design. These studies only looked at non - governmental institutions within a different geographical region and setting and therefore their performance cannot be measured to public institution specifically the government institution.

There is also a lot of inconsistencies on whether age, gender and ethnicity positively or negatively impacted on performance. This is because some researchers agreed that they either positively or negatively impacted on organizational performance or both

\subsection{Research Design}

Research design entails how the study will be conducted. It utilized longitudinal research design as the study seeks to make observations over specific period of time. The observable features in the study indicate the changes within that period that are easily comparable.

\subsection{Data collection}

Secondary methods of data collection were used. It will be obtained from the documented yearly reports and personnel records of the institution to collect data for a period of 10 years showing quarterly reports on the number of cases resolved. Information on the demographic characteristics of the workforce will be derived from the personnel records (2019) at the organization. This is because through secondary data that is possible to understand the history of performance in relation to Kisumu Law Court that enabled the crosschecking of official information, learning about major previous events and various historical decisions.

\subsection{Data analysis}

The study used descriptive statistics frequencies, standard deviation and percentages was used to analyze data. Multiple regression model was used to determine correlation between diversity constructs and organizational performance. The predictor variables $\mathrm{X} 1, \mathrm{X} 2 \ldots . \mathrm{X} 4$ will provide findings in its relation to the variable $\mathrm{Y}$ from the equation derived from the data observed and its association to the same. The SPSS program was used know which variable will be included in the final equation. ANOVA statistics was used to confirm the goodness of using the level of significance of the regression model. The following equation was be used:

$\mathrm{Y}^{\prime} \mathrm{i}=\beta 0+\mathrm{b} 1 \mathrm{X} 1 \mathrm{i}+\mathrm{b} 2 \mathrm{X} 2 \mathrm{i}+\mathrm{b} 3 \mathrm{X} 3 \mathrm{i}+\mathrm{b} 4 \mathrm{X} 4 \mathrm{i}+\ldots \mathrm{bkXki}$

Where,

$\mathrm{Y}_{\mathrm{i}}^{\prime}=$ Organizational performance

$\beta 0=$ constant (coefficient of intercept)

$\mathrm{X}_{1}=$ Education diversity index

$\mathrm{X}_{2}=$ Gender diversity index

$\mathrm{X}_{3}=$ Religion diversityindex

$\mathrm{X}_{4}=$ Ethnic diversity index

$\mathrm{B}_{1} \ldots \mathrm{B}_{4}=$ regression coefficient of four variables 


\section{Data Analysis, Findings And Discussions}

\subsection{Introduction}

This chapter reports on findings on the effect of workforce diversity on organization performance of Kisumu Law courts. It will show the demographic information on diversity, predictors of organizational performance and their relationship and discussions according to the findings of the study.

\subsection{Demographic information}

Demographic information will provide details of the study in relation to their gender, educational background, ethnicity and religion being also the independent variables of the study.

Table.1: Distribution of Gender

\begin{tabular}{lll}
\hline Gender & Frequency & Percentage \\
Male & 62 & $47.33 \%$ \\
Female & 69 & $52.67 \%$ \\
Total & 131 & $100 \%$ \\
\hline
\end{tabular}

Source: Personnel records 2019

Table 1 indicates that among the 131 employees, majority (52.7\%) was female and Table 2:Distribution of Educational background

\begin{tabular}{lll}
\hline Level of education & Frequency & Percentage \\
Master's degree & 14 & $18.34 \%$ \\
Bachelor's degree & 28 & $21.37 \%$ \\
Diploma & 37 & $28.24 \%$ \\
Certificate & 12 & $9.16 \%$ \\
Others & 40 & $30.53 \%$ \\
Total & 131 & $100 \%$ \\
\hline
\end{tabular}

In terms of the educational background, majority (30.5\%) had other educational background,( $28.2 \%$ ) of them had diplomas, $(21.37 \%)$ had Bachelors degree,(18.34\% had Masters degree while about (9.2\%) had attained certificate level of education. This indicates that there is diversity in education amongst the employees of the Kisumu law courts since the participants had different levels of education.

Table 3:Distribution of Religious background

\begin{tabular}{lll}
\hline Religion & Frequency & Percentage \\
Christian & 128 & $97.7 \%$ \\
Islam & 3 & $2.3 \%$ \\
Total & 131 & $100 \%$ \\
\hline
\end{tabular}

Most of respondents in the study were Christians (97.7\%) while( $2.3 \%)$ of them were from the Islam religion. The highest inclusion of Christians since majority of the residents of the study area are Christians.

Table 2: Distribution of Ethnic background

\begin{tabular}{lll}
\hline Ethnicity & Frequency & Percentage \\
Luo & 55 & $41.98 \%$ \\
Luhya & 27 & $20.61 \%$ \\
Kisii & 17 & $12.98 \%$ \\
Kamba & 2 & $1.53 \%$ \\
Kuria & 4 & $3.1 \%$ \\
Kalenjin & 12 & $9.2 \%$ \\
Teso & 1 & $0.76 \%$ \\
Burji & 1 & $0.76 \%$ \\
Bajun & 1 & $0.76 \%$ \\
Kikuyu & 5 & $3.8 \%$ \\
Meru & 1 & $0.76 \%$ \\
Suba & 5 & $3.8 \%$ \\
& & \\
Total & 131 & $100 \%$ \\
\hline
\end{tabular}


In terms of the ethnic background, $41.98 \%$ were from the Luo community, Luhya were $20.61 \%, 12.98 \%$ came from the Kisii background, $1.53 \%$ were from Kamba origin,3.1\% Kuria,9.2\% came from the Kalenjin Community, Teso, Burji, Meru and Bajun was the lowest with $0.76 \%$ while Kikuyu and Suba had 3.8\%.

\subsection{Predictors of organizational performance.}

The model summary provides the $\mathrm{R}$ squared which is the measure of the goodness of fit. It explains the changes between the variables (performance of Law courts) as explained by the independent variables (Gender, Education, Religion and Ethnicity). The value of $\mathrm{R}$ squared is 0.729 ; therefore this implies that $72.9 \%$ of the difference reflects that with the independent variables.

Table 5: Predictors of organizational performance.

\begin{tabular}{llll}
\hline Model & R & R Square & Std. Error of the Estimate \\
\hline 1 & $.854^{\mathrm{a}}$ & .729 & .248 \\
\hline
\end{tabular}

The ANOVA statistics indicated that the p-value (0.026) was less than 0.05 . This indicated that gender diversity, education diversity, religion and ethnic diversity have a significantly affects the performance of the Kisumu law courts. It is an indication that there is significance in showing the results of the independent variables (gender diversity, education diversity, religion diversity and ethnicity) and the performance of law courts.

Table 6:Analysis of Variance.ANOVA ${ }^{\mathrm{a}}$

\begin{tabular}{|c|c|c|c|c|c|c|}
\hline Model & & $\begin{array}{l}\text { Sum } \\
\text { Squares }\end{array}$ & of $\mathrm{Df}$ & Mean Square & $\mathbf{F}$ & Sig. \\
\hline \multirow{3}{*}{1} & Regression & 1.793 & 4 & .448 & 7.302 & $.026^{\mathrm{b}}$ \\
\hline & Residual & .307 & 5 & .061 & & \\
\hline & Total & 2.100 & 9 & & & \\
\hline
\end{tabular}

a. Dependent Variable: Organizational performance

b. Predictors: (Constant), gender index, ethnicity index, religion index, education index.

Multiple regressions was used to determine the predictors of organizational performance. Findings indicated the gender index was positively associated with organizational performance. Findings show that a rise in the gender index increases the organizational performance by 1.27 units as shown in Table 7.However, there was no association between education, ethnicity and religion diversity and performance of the organization $(\mathrm{p}>0.05)$. In reference to the model equation in the $Y=\beta_{0}+\beta_{1} X_{1+} \beta_{2} X_{2}$ where $Y$ is organizational performance, $X_{1}$ gender index ,X2 is the ethnicity index ,the fit equation is : Organization Performance $=-3.15+1.27 *$ gender diversity $+0.035 *$ Ethnicity diversity + $0.305 *$ Education diversity $+0.56 *$ Religion diversity

Table 7: Regression between organizational performance and diversity

\begin{tabular}{llllllll}
\hline Model & \multicolumn{2}{l}{$\begin{array}{l}\text { Unstandardized } \\
\text { Coefficients }\end{array}$} & $\begin{array}{l}\text { Standardized } \\
\text { Coefficients }\end{array}$ & & & Sig. & \multicolumn{2}{c}{ Collinearity Statistics } \\
\cline { 2 - 4 } & B & Std. Error & Beta & & & Tolerance & VIF \\
\hline (Constant) & -3.150 & 1.081 & & -2.915 & .033 & & \\
Religion index & .559 & .232 & .559 & 2.414 & .061 & .545 & 1.835 \\
Ethnicity index & .035 & .047 & .165 & .750 & .487 & .605 & 1.654 \\
Education index & .305 & .134 & .599 & 2.281 & .071 & .423 & 2.363 \\
Gender index & 1.269 & .245 & 1.384 & 5.187 & .004 & .410 & 2.437 \\
\hline
\end{tabular}

a. Dependent Variable: Organizational performance

\subsection{Discussion of findings}

This study found out that gender, ethnicity, religion and educational background were associated to organizational performance. It indicated that the gender of workforce influences the performance of the organization which are consistent with Kyomugisha, (2016) of international NGOs in Kenya which established that gender diversity indicators influenced performance of NGOs in Kenya. Similarly, the findings are in agreement with Gupta, (2013) study established that gender impacted on the performance of orghanizations. Kerby and Burns,(2012)found out that equal gender representation helped in boosting the economy of the state nation and gender balance being a significant factor in achieving organizational performance.Welliang et.al.,( 2012) study also established that gender diversity and performance were positively related. Aliet al., (2000) established that differencein gender was a great source for an organization to enjoy competitive edge hence improves the organizational performance. 
Similary, Knippenberg, et al., (2014) established that gender inclusion fostered good service delivery in performance by stating that by improving the decision making process hence proper strategy formulation. Moreover, (Richard, 2006) study indicated correlation between performance of businesses and difference in gender respectively. Similarly, Omankhanlen et al., (2011) study found out that diversity in gender associated positively with organizational effectiveness. The study recommended organizations to use strategies to manage workforce diversities in order to achieve organizations goals. Further the findings are also in line with Akpakip, C. E. (2017) study which established that gender diversity impacts the employee performance positively. Gender balance eliminates inconsistences in employee performance. Organizations that provide for gender balance for all employees avoid discrimination from the workplace .This shows that work relationship is improved despite differences due to gender. Ali et al., also found out that organizations that appreciate gender inclusion in work are able to survive and compete effectively as they tend to enjoy more benefits.

The findings were also inconsistent with Gupta, (2011) study which shows that diversity in gender affected the performance of organizations negatively. Ely, (2004) study in the United states on banks found no effect of gender to performance. Busolo, (2017) established that gender diversity had a negative association with organization performance. Jehn et al., (2004) study also found out that diversity in gender impacted negatively on performance either as an individual or collectively. According to Marimuthu and Kolandaisamy, (2009) established no association between gender diversity and the performance of Malaysian companies.

On education, religion and ethnicity diversities found out that there was no association to organizational performance because the findings were statistically insignificant as $p>0.05$.However on education this finding is inconsistent with that of Ogbo and Ukpere 2014 that found out that education was a great motivational tool to diversity management that helps to improve productivity within the organization.

The findings are related to cognitive diversity as peoples, knowledge, perception and experiences to handle issues of complexity such as workforce diversity promote good performance. Similarly Naqvi.et al, 2013study indicated that gender diversity boosts the team work of the employees. There is also a positive relation due to the fact that the different perspectives brought in by the diverse nature such as gender create an environment to be able to adjust tow work challenges, foster creativity and innovation and thus improve organizational performance.

\subsection{Summary of findings}

The objective of the study was to establish the influence of workforce diversity on the performance at Kisumu Law courts. The study adopted a longitudinal research design used to show the association between the workforce diversity and performance. Secondary data was used. Among 131 records used for the study, majority (52.7\%) were female and $47.3 \%$ were male. Moreover, majority (30.5\%) had other educational background, $28.2 \%$ of them had diplomas while about $9.2 \%$ had attained certificate level of education. Further, Christians $(97.7 \%)$ while $2.3 \%$ of them were from the Islam religion and $42 \%$ were from the luo community while only $3.8 \%$ were from the Suba community. After analysis by regression, the R Square value showed that $72.9 \%$ of the variation could be included in by the independent variables.

Overall, based on the multiple regression analysis, gender diversity was significantly associated with the organizational performance at Kisumu Law Courts, Kenya i.e Organization Performance $=-3.15+1.27$ *gender diversity $+0.035 *$ Ethnicity diversity $+0.305 *$ Education diversity $+0.56 *$ Religion diversity. Diversity in gender showed a positive association to organizational performance. However, there was no statistical association between the education diversity, ethnicity and religion diversity to the performance of Kisumu Law Courts, Kenya.

\subsection{Conclusions}

The study sought to determine on the influence of gender, ethnicity, religion and education diversity on the performance of Kisumu Law Courts, Kenya. Diversity is an important tool in ensuring organizational productivity however it must be well managed to achieve performance. From the findings gender difference was statistically associated to performance. Adequate and proper gender inclusion fosters a conducive working condition that brings out diversity in gender to promote teamwork and hence improves workforce thus increase in the desired yield. Gender balance in the organization has shown to improve the achievement of the organizational objectives. This is because gender diversity increases diversity in innovations, creativity and change of ideas the help boost the effectiveness of most organizations. 


\subsection{Recommendations}

The study recommends that regulations and policies should be initiated in organizations that promote workforce diversity such as gender balance during recruitment, ethnic balancing, reward systems and respect for each other's religion in order to enhance good working relationship and environment. The managers responsible for policing implementation should ensure a good working environment and promote organizational culture because the lack of it would lead to discrimination that result to organizational conflicts and hence performance is hampered as a result of ethnic divisions

. Trainings can be organized touching on workplace diversity and teamwork in order to bridge any ethnic groupings which may impact the organizational performance negatively.

More emphasis and attention to be put on the education because lack of it mean that there is knowledge gap that needs to be filled and as such work is hampered with.

\subsection{Limitation of the studies}

The study was limited to only one High Court in Kenya. Only secondary data was used in gathering information. The study only looked at the demographic diversity variables. It was also limited to one method of data collection that is, only secondary data was used. On methodology the research was limited only to longitudinal research design that was time consuming because of the large amounts of data required as well as the accuracy of the data may not be heavily relied on.

\subsection{Suggestions for further studies}

The findings of this study suggest the need for more research to establish the effect of cognitive diversity variables on performance of the organizations. The study recommends further research work to be done in other High Courts of Kenya to enable comparability. The method of data collection for further studies used should be primary and secondary data to improve on the accuracy of the data collected. More studies should use cross sectional survey as it is not costly and time consuming because the data collected is specific and is done only once.

\section{References}

Adler, N. J. (2005). International Dimensions of Organizational Behavior (4th Ed.). Cincinnati, OH: South-Western Alice Kyomugisha, (2016).The effect of workforce diversity on performance of international development Non governmental organizations in Kenya

Akpakip, C. E. (2017). Effect of Workforce Diversity on Employee Performance in Nigerian Banking Industry (A Study Of Firstbank Nigeria Ltd., Ota Branch) (Doctoral dissertation, Covenant University, Ota, Nigeria.).

Bandura, A. (1989). Social cognitive theory. In R. Vasta (Ed.), Annals of child development. Vol. 6. Six theories of child development (pp. 1-60). Greenwich, CT: JAI Press.

Busolo, E. (2017). The Impact of Workforce Diversity on Organizational Performance: A Case Study of Aar Group (Doctoral dissertation, United States International University-Africa).

Aydin, M.K. (2013). British multiculturalism: Diversity issues and development of multicultural education in Britain. In H. Aydin (Ed), Multicultural Education: (pp58-91. Saaebruken: LAP LAMBERT Academic Publishing

Berschieid, Ellen, and Elaine H.Walster, (1969) Rewards Others provide: Similarity in Interpersonal Attraction, 69 - 91

Byrnes, J. F. (1986). Costing Human Resources: The Financial Impact of Behavior in Organizations. . The Academy of Management Review (4th ed., Vol. 9).Cincinnati, $\mathrm{OH}$.

Cole, G. A. (2004). Management Theory and Practice. . Southwestern MA: Cengage Learning.

Cox, T. (1991). Managing Cultural Diversity: Implications for Organizational Competiveness. . Academy of Management Executive, 5, 45-56.

Dike, P. (2013).The impact of workforce diversity on organizations. Retrieved from https://www.theseus.fi/bitstream/handle/10024/63581/Thesisxx.pdf?sequenc

Enid Busolo. (2017).The effect of workforce diversity on organizational performance of AAR group.

Greer, L. L., \&Jehn, K. A. (2007).Chapter 2 the pivotal role of negative affect in understanding the effects of process conflict on group performance. Emerald Group Publishing Limited.

Greenberg, M. (2004). Group composition and decision making: How member familiarity and information distribution affect process and performance. Organizational Behavior and Human Decision Processes, 67, 1-15.

Gonzalez, J.A. and Denisi, A.S. (2009), "Cross-level effects of demography and diversity climate on organizational attachment and firm effectiveness", Journal of Organizational Behavior, Vol. 30 
Gupta, R. (2011). Workforce Diversity and Organizational performance. International Journal of Business and Management Invention, 2(6), 36-41.

Gupta, R. (2013). Workforce diversity and organizational performance. International journal of business and management invention. (Online) Available: www.ijbmi.org

Hambrick, Jauhari, H., \& Singh, S. (2013). Perceived diversity climate and employees' organizationalloyalty. Equality, Diversity \& Inclusion, 32(3), 262-276. doi:10.1108/EDI-12-2012-0119

Harold, A. P., \&Vincent. K. R. (2012). Managing Workforce diversity: Issues and Challenges. Sage Journals.

Hoogendoorn, S., Oosterbeek, H., \& van Praag, M. (2015). The Impact of Gender Diversity on the Performance of Business Teams: Evidence from a Field Experiment. Electronic Journal, , 1-3.

Hoogendoorn, S., Oosterbeek, H., \&Praag, M.V., (2013). The impact of gender diversity on the performance of business teams: Evidence from a field experiment. Management Science Articlesin Advance, pp.1-15.

Ikama, A. (2010). Benefits and challenges of workforce diversity: a case study of Consultative Group on International Agricultural Research (CGIAR) Centres in Kenya. Nairobi: Unpublished MBA research report.

Jepchirchir, B. N. (2015). Challenges of managing workforce diversity at the ministry of mining, Kenyan civil service. Nairobi: Unpublished MBA of University of Nairobi.

Kabeer, N. (2005). Gender equality and women's empowerment: A critical analysis of the third millennium development goal 1. Gender \& Development, 13, 13-24.

Kathimba, E. M., \&Anyieni, A. (2019). Effect of workforce diversity on performance of National Police Service in Nakuru County, Kenya.International Academic Journal of Human Resource and Business Administration; Volume 3, Issue 1, 150-169.

Kerby, S., \& Burns, C. (2012). The top ten diversity facts in the workforce: A diverse workforce is integral to a strong economy.Center for American Porgress.

Kerby.K.,\& Burns. C. (2012). The top 10 economic facts of diversity in workforce. Retrieved from the Center for Progress website: http://www.americanprogress.org

Kossek, E., Lobel, S., \& Brown, A. (2005). 'Human Resource Strategies to Manage Workforce Diversity. In P. P. A.M. Konrad, Handbook of Workforce diversity, eds. Thousand Oaks, CA: Sage.

Kerga, A. B., \&Asefa, A. (2018). The Effect of Workforce Diversity on Employee Performance (The Case of EthioTelecom South West Addis Ababa Zone). Asian Journal of Economics, Business and Accounting, 1-27.

Kothari, C. (2011). Research Methodology: Methods and Techniques. Second Edition. India: New Age International publishers.

Lawler, J. J., Chen, S., Wu, P., Bae, J., \&Bai, B. (2011). High-performance work systems in foreign subsidiaries of American multinationals: An institutional model. Journal of International Business Studies, 42(2), 202-220.

Maingi, J. W., \&Makori, M. (2015). Effect of workforce diversity on organizational performance in Kenya: a case of Kenya School of Government. Vol. 2 (59), pp. 343-364, July 15.

Magoshi, E., \& Chang, E. (2009).Diversity management and the effects on employee's organizational commitment: Evidence from Japan and Korea. Journal of World Business, 44(1), 31-40.

Muasa, D. N., Egondi, P., \&Mathuva, E. (2017). Effects of Primary Factors of Workforce Diversity on Organizational Performance: International Journal of Scientific Research and Innovative Technology ISSN: 2313-3759 Vol. 4 No. 9.

Mugenda, O., \&Mugenda, A. (2010).Research Methods Qualitative and Quantitative Approaches. Nairobi: Kenyatta University, Nairobi Act Press.

Muthiora, D. M. (2017).Workforce diversity and organizational performance in National Biosafety Authority, Kenya. Nairobi: Unpublished MBA reseach of UON.

Mwatumwa, A. S. (2016). Effect of workforce diversity on employee work performance: A study of the county government of Mombasa.

Myers, M. D. (2009). Qualitative Research in Business \& Management, London: SAGE.

Naqvi, S. R., Ishtiaq, M., Kanwal, N., Butt, M. U., \& Nawaz, S. (2013). Impact of gender diversity on team performance: The moderating role of organizational culture in telecom sector of Pakistan. Asian Journal of Social Sciences \& Humanities, 2(4), 228-235.

Niemann, R. (2006). Managing workforce diversity in South African schools South African Journal of Education Vol 26(1), 97-112.

Oduor, C., \&Ogejo, W. (2015).Diversity Management and Pluralism in Kenya's Major Private Sector Firms. Nairobi: Institute of Economic Affairs.

OECD. (2011). Public Servants as Partners for Growth: Toward a Stronger, Leaner and More Equitable Workforce,

Ogbo, A. I., Kifordu, A., \&Ukpere, W. (2014). The effects of workforce diversity on organizational performance of selected firms in Nigeria: Mediterranean Journal of social sciences. MCSER Publishing, Rome- Italy. 
Oyedela Ola Olusegun, IssaAbdulraheem\&BrimahAminu Nassir. 2017. Workforce diversity startegiews and organizational performance in the food and beverage Industries in Nigeria. Vol 05, Issuee 01

Omankhanlen, A. E., \&Ogaga-Oghene, J. (2011). The impact of workforce diversity on organizational effectiveness: a study of a Nigerian bank. Annals of the University of Petroşani, Economics, 11(3), 93-110.

Pitts, D. (2010). Diversity management, job satisfaction, and performance: Evidence from U.S. Federal Agencies. Public Administration Review, 69(2), 328-338.

Richard, O. (2006). Racial diversity, business strategy and firm performance: a resource-based view, Academy of Management Journal, Vol. 43, pp. 164- 77.

Shen, J., Chanda, A., D’Netto, B., \&Monga, M. (2009). Managing diversity through human resource management: an international perspective and conceptual framework. International Journal of Human Resource Management, 20(2), 235-251.

Tajfel, R. (1978). Managing Diversity, A Strategy 'Grass Roots Approach, In S.E. Jackson and others (Eds), Diversity in the Workforce: Human Resource Initiatives, 1. New York: Guilford Press.

Taylor, C. (2015). 2015 the year of diverse workforce: Human capital magazine online. Key media pty Ltd.

T. Simons, L. Pelled and K. Smith, "Making use of difference: diversity, debate, and decision comprehensiveness in top management teams. "Academy of Management Journal, vol. 42, no. 6, pp. 662-673, 1999.

Turner, J, C., \&Tajfel, H. (1986). The social identity theory of intergroup behavior, Psychology of intergroup relations, $7-24$

WebiRecadina\& Dr. CarenOuma (2017). Effects of board diversity on performance of Non - governmental Organizations in Nairobi County in Kenya. Vol. 6 Issue 7

Walster, E., Walster, G. W., \&Berscheid, E. (1978).Equity: Theory and research.

Yamane, T. (1967).Elementary Sampling Theory. Engle weed Cliff: Prentice Hall Inc.

M. Marimuthu and I. Kolandaisamy, "Ethnic and Gender Diversity in Boards", Journal of Sustainable Development, vol. 2, no. 3, 2009.

A. Ogbo, K. Anthony and W. Ukpere, "The Effect of Workforce Diversity on Organizational Performance of Selected Firms in Nigeria", Mediterranean Journal of Social Sciences, 2014.

J. Leonard and D. Levine, "The Effect of Diversity on Turnover: A Large Case Study", ILR Review, vol. 59, no. 4, pp. 547-572, 2006. 